\title{
A Taiwanese University's Initiatives for COVID-19 Prevention: Implications for Teachers and Students
}

\author{
Jeffrey Hugh Gamble* \\ Department of Foreign Languages, National Chiayi University, Taiwan
}

*Corresponding author: Jeffrey Hugh Gamble, National Chiayi University, 85 Wenlong Village, Minhsiung County, Chiayi, 62103, Taiwan

ARTICLE INFO

Received: 蔧 May 26, 2020

Published: 橎 June 03, 2020

Citation: Jeffrey Hugh Gamble. A Taiwanese University's Initiatives for COVID-19 Prevention: Implications for Teachers and Students. Biomed J Sci \& Tech Res 28(1)2020. BJSTR. MS.ID.004594.

Keywords: Taiwan; COVID-19; Pandemic Prevention Measures; University Initiatives; Teachers; Students

Abbreviations: CDC: Centers for Disease Control; CECC: Central Epidemic Command Center; PPE: Personal Protective Equipment; SMS: Short Message Service; IC: Integrated Circuit; RT-PCR: Reverse Transcription Polymerase Chain Reaction; MOE: Ministry of Education

\author{
ABSTRACT
}

Taiwan's response to the COVID-19 epidemic has gained praise from governments and news outlets around the world. Actions taken by the Taiwan Centers for Disease Control (CDC) and, later, by the Central Epidemic Command Center (CECC) have to date limited the number of cumulative infections to under 450 (which is less than 19 cases per million) and the number of deaths to seven (which is .29 cases per million). Noteworthy measures taken by the government to limit the spread of SARS-CoV-2 virus include early suspension of air travel, leading to an eventual ban on non-residents entering Taiwan, active and technology-enhanced contact tracing, mandatory wearing of surgical-grade masks in public, enforcement of social distancing, wide-spread use of temperature checks, mandatory 14 day quarantines with electronic monitoring, and effective use of media (including daily press conferences and the release of virus prevention infographics). Most impressively, to date, no lockdown measures have been required, and no local transmission of the virus has been observed since April 12, 2020. Additionally, local, county- and city-level initiatives were also enforced, often depending on the number of cases in that particular jurisdiction. Of particular interest to this paper is the role of universities in autonomously adopting standards and practices related to COVID-19 prevention, and the potential impacts on teaching and learning. The case highlighted in this article is from a large public university in Southern Taiwan. Frequent communications by the school to faculty, staff, and students set guidelines for health self-evaluation and monitoring, infection prevention measures and safeguards, classroom arrangement and conduct, and preparations for online teaching in the case of potential lockdown. While lockdown has been avoided, disruptions to teaching schedules have been unavoidable, and the flexibility of teachers and students has been instrumental overcoming the potential obstacles of an uncertain semester.

\section{Introduction}

The COVID-19 pandemic of 2020 has offered both researchers and the general public a great deal ofinformation, ranging from "fake" and sometimes dangerous news, largely shared on social media, to open access to peer-reviewed academic studies and datasets. From a positive perspective, many lessons can be learned from the actions taken by different countries and regions around the globe. One example that has been help up as a model of a balanced approach to COVID-19 prevention has been that of Taiwan [1]. Taiwan has avoided unnecessary lockdowns on one hand, while enforcing hygienic and preventative measures on the other. Early detection of cases being reported on Taiwanese social media platforms informed authorities of the potential spread of a new coronavirus much earlier than many countries, due to proximity to mainland
China. As such, implementation of airport screening, quarantining of suspected cases, and in-depth contact tracing initially resulted in few locally transmitted cases [2], with no new locally transmitted cases reported since April 12, 2020. The first case was confirmed in Taiwan on January 21, 2020, with Taiwan implementing increasingly broad travel restrictions from known COVID-19 hotspots starting in January which, in addition to self-quarantine measures and citizens' observed behavioral changes in terms of limiting social interactions and mobility within the community, are believed to have impacted the effectiveness of Taiwan's containment measures [3]. The use of social media surveillance, real time risk assessment, and proactive border protection measures allowed Taiwan to enact quarantine requirements by country or region, based on current 
conditions, such as the requirement for travelers from South Korea to quarantine on February 24 and those from Italy on February 27 [4].

Due to the increasing number of suspected and confirmed cases in February and March, hospitals implemented mandatory wearing of masks, hand sanitization, infrared temperature detection, and the use of buffer zones to separate patients with different risk levels of having COVID-19 [5,6]. Clinical and epidemic criteria changed according to evolving knowledge of the disease, particularly during February and March 2020 [7], which, in conjunction with public announcements, guided residents to call a toll-free number, 1922 , in order to first report symptoms, rather than immediately visit a clinic or hospital. Other measures related to hospital care of potential infections include the government's oversight and distribution of personal protective equipment (PPE), limitation on hospital visitors [8], regular disinfection of equipment and facilities, and triaging of cases, all based on Taiwan's experience with the SARS epidemic of 2003 [9,4]. The use of technology in combatting the disease ranged from cellphone short message service (SMS) messages for keeping track of persons under self-quarantine and QRCode scanning for completion of a mobile declaration pass to the use of applications for finding masks during temporary shortages and social media for receiving updated official information on the virus [10]. Furthermore, visitors and citizens were asked to turn on location-tracking functions, such as those provided through Google Maps, in order to trace movements that may later be used by healthcare professionals for contact tracing in the case of infection [11], in addition to the use of travel and health history data available from Taiwanese residents' integrated circuit (IC) chip health cards [12].

Extensive use of technology illustrates the potential application of Big Data analytics in effective contact tracing and tracking [13] with some evidence even suggesting that Google searches can be used as an index for predicting a rise in cases (according to location) following a lag of a few days [14]. In order to further researchers' understanding of the situation in Taiwan, press releases by Taiwan's Centers for Disease Control [15] are available online and contain detailed information regarding COVID-19 cases, including demographic data, travel history, disease onset date, symptoms, and date of confirmation using reverse transcription polymerase chain reaction (RT-PCR) tests [2], a test that is believed to be essential to accurate diagnosis based on inconsistent results from chest radiology [16]. This has further informed researchers and practitioners in the ongoing battle to test, confirm, and treat cases. This paper emphasizes the role of universities, due to the degree of autonomy provided to them in terms of how schools enforce pandemic prevention guidelines, and how teaching and learning would be conducted. The following case will highlight the precautionary measures administered by one university in Taiwan and some preliminary outcomes.

\section{Case Report}

The case covered by this paper is of a large public university in Southern Taiwan. Consisting of three campuses, seven colleges, and 36 departments, with over 500 full-time faculty members, the university attracts students from around Taiwan, as well as other countries. As such, students frequently travel to their hometowns during weekends and holidays, by rail or bus, while international students often return to their home countries for winter and summer breaks. Taiwanese students also enjoy travelling during longer breaks. As a result, several returning international students and local students were isolated for the first two weeks of the semester due to the recently enacted self-quarantine measures. For these students, instructors were responsible for providing opportunities for make-up classes or assignments, which, in cases, included the use of online teaching. As early as February 2 concerns arouse regarding the potential of a delay in the semester start date and the process for taking leave if necessary due to the virus. On February 6, the university disseminated information regarding COVID-19, including guidelines for enforced quarantine, self-quarantine, and health self-management. On February 13, the meeting memos from a meeting of the school administration revealed several developments: updates on the status of international students, preparation of alcohol sanitizer and forehead infrared thermometers, the establishment of a "Epidemic Prevention and Health Education Information Group," the posting of epidemic prevention infographic posters across the campuses, preparation for online teaching in collaboration with the Computer Center, oversight of potential curricular modifications, such as online teaching, by the Office of Academic Affairs, preparation of letters to parents explaining any delays in the semester, the provision of psychological support resources, student dormitory arrangements, and potential provisions for contact tracing.

Ultimately, the beginning of the semester was postponed by two weeks, from February 17 to March 3. This university was one of the last to make this announcement (with many universities making announcements as early as February 2), while the Ministry of Education (MOE) at the same time had proposed a delay for elementary to high school students until February 25. The MOE guidelines would later state that if two cases occurred at the same school, classes must be suspended. On February 21, the university announced that the Ministry of Education had approved a delay of two weeks, with flexible course planning to ensure a full 18 week (standard duration) semester. At the same time, a PPT file was disseminated which contained several options for handling the delayed semester, with the responsibility for decision-making placed upon the instructor:

1) 16 week semester: Weeks 17 and 18 can be made up by one of the following methods:

a. Rescheduling classes during holidays, weekends, or other free times; 
b. Continual teaching with no breaks between periods (a ten minute break is normally scheduled) with an additional four minutes after class to make up for 18 weeks of class time within a 16 week timeframe; or

c. Other types of instruction, such as attending speeches, holding Q\&A sessions, off-campus visits, or alternative methods.

2) 17 week semester: Week 18 would be made up using one of the above-mentioned methods.

3) 18 week semester: The last week of class would be postponed until the week of June 29.

Due to the fact that the majority of students disliked the idea of a delayed summer vacation, the majority of instructors opted for the option of a 16 week semester, with various teachers adopting different methods for making up for the final two weeks. This caused hardship for teachers and students, as contact time, preparation time, and demonstration/assessment time was reduced. Many teachers offered online resources for students, requiring them to complete reports, while others chose to have make-up classes when students had no other classes. A few teachers did select the option of continual teaching without breaks. Implications of the 16 week semester were felt by all teachers, as an 18 week syllabus had already been approved and uploaded to the university website, and students had already registered for classes. Modifications to the schedule resulted in some missed content and the lack of time for students to adequately prepare for assignments, as compared to the regular 18 week semester. However, due to Ministry of Education guidelines, students were required to complete sufficient hours to qualify for credits. At this time, the beginning of the delayed semester (March 4), the university president sent a letter to faculty and students entitled "Hoping We are Safe and Healthy," which addressed the delayed school semester, the quarantine of student arriving from abroad, the schools efforts to disinfect every area of the campus, and an encouragement for everyone to wear masks, although they were not mandatory island-wide at the time. At the same time, a PDF file was sent with instructions for faculty and students to fill in information on their travel history, current symptoms (fever, cough, throat pain, shortness of breath, runny nose, muscle or joint pain, and others), potential contact with infected individuals, or current self-isolation status. This form was offered on the school's online administration website and is available to be filled out each week. Further weekly information on student seating and online attendance was required by the school Teachers were asked to assign students to specific seats and then submit the seating arrangement every week. The rationale was that student seating information could be used for contact tracing if required at any point.

Constant information was provided by the university. The content was often based on government press releases [15] which contained easily understood infographics, visualizations, and simple instructions for disease prevention, including topics such as hand washing, acquisition and use of masks, typical symptoms, and contact information for consultation. The university commonly posted these on the homepages of various departments and offices (such as the Health Care Group, Office of Student Affairs, and Office of Academic Affairs) and emailed this information to individual departments, as well as faculty and student accounts. As of now, nearly 200 individual and unique documents, posters, and announcements have provided by the university to teachers and students through these various channels. In order to augment these online information sources, calls from the university's health center were made, particularly at the beginning of the semester, in order to check on those who might have travelled abroad over the winter break, as well as to provide basic infection prevention information. Such calls from professional medical staff are critical given the findings of [17] that professional health care worker contact was associated with positive psychological well-being for Taiwanese respondents as compared to relatively negative psychological well-being for respondents who relied upon online sources of information, particularly those provided by social media.

Policies were frequently updated and reminders sent regarding on-campus regulations. For example, on April 4, 2020, the university sent an official document (which first reminded faculty and students of their social responsibility) highlighting the following essential regulations:

1) Social distancing is to be maintained and public gatherings and public transportation are to be avoided whenever possible. If these cannot be avoided, which includes large classes of students, masks must be worn at all times.

2) Indoors, a distance of 1.5 meters is to be maintained at all times, while outdoors the required distance is 1 meter. However, in the case of close proximity within classrooms, everyone must wear a mask.

3) Body temperature is regulated at the entrance to each campus. Those with a fever (defined in other documentation as a forehead temperature $\geq 37.5^{\circ} \mathrm{C}$ or tympanic temperature $\geq$ $38.0^{\circ} \mathrm{C}$ ) are not allowed on campus

4) Hands must be sanitized whenever entering an office or classroom with $75 \%$ alcohol.

5) No food or drink is allowed in classrooms, and all beverages must have lids.

6) It is recommended to bring your own pen to use for signatures and avoid handshakes.

7) When eating on or off campus, 1.5 meters of separation should be maintained and talking should be prohibited when a mask is not being worn. 
While the discomfort with wearing masks was a common complaint from both teachers and students, including the added difficulty in understanding one another and breathing well, compliance was nearly $100 \%$. Frequent hand washing was encouraged and was not considered a burden. Students who were accustomed to eating breakfast or drinks in class were encouraged to use break times to go outdoors to do so. As such, the aforementioned requirements were deemed necessary to prevent transmission from potentially presymptomatic or asymptomatic cases. In compliance with government regulations, information was passed to teachers and students, advising the use of location-tracking functions when travelling off-campus This was particularly important for the Tomb-Sweeping Festival mid-term break (which was a total of nine days from March 28 to April 5, 2020). Before the holiday, on March 26, the university president wrote a letter to students, entitled "A Different Spring Break," advising students to observe social distancing, wear masks, frequently wash their hands, avoid touching their face, and avoid getting together with friends during this dangerous time. At the same time, the Taiwanese government was under some criticism for not enacting travel restrictions, since tomb-sweeping involves close proximity to non-family members and the accompanying holiday often involves travel to different parts of the island. Nevertheless, before the break, the CECC did warn travels to take precautions and observe social distancing as much as possible. Thankfully, only a few students required quarantine due to exposure to an individual who was a potential contact of a COVID-19 confirmed case. No cases for the university were reported, so no lockdown and cancellation of face-to-face classes was required.

The week prior to the spring break, instructors were also required to complete a form indicating their plans to implement online teaching in the case of a shutdown, which was being discussed on social media and by some media outlets as a possibility at the time. During March, the Computer Center distributed information on how to use synchronous and asynchronous technologies for teaching, and offered in-person counselling and professional development courses for the use of these platforms. The March 20 email indicated that instructors were to fill in an Excel document with the following information for each course they were teaching:

1) Online teaching method (synchronous, asynchronous, or other);

2) Evaluation method (Online tasks, discussions, tests, or other); and

3) Practicum-related coursework.

In terms of synchronous computer mediated instructional platforms, the university recommended Zoom, CyberLink U Meeting, Microsoft Teams, Cisco WebEx, Adobe Connect, and Google Hangouts Meet. Later, on April 7, the school and the Ministry of Education announced that due to privacy and security issues, Zoom should no longer be used. In terms of asynchronous platforms, the university recommended using video or screen recording software. All instructors were required to upload these plans, and to discuss the possibility of implementing online teaching with their students in the case of a lockdown. Students and teachers generally demonstrated distaste for the use of online teaching for several reasons: the lack of immediacy, difficulties in completing group work, assessment and attendance issues, and technical and time limitations, to name a few. As public university employees, protections were in place in case of infection, allowing instructors to take leave without penalty and, when appropriate, receive disease prevention compensation [18]. Students were also protected from unfair penalization in the case of required quarantine or illness. Their absences would not be registered in the online attendance record, and professors were required to provide them with makeup options.

\section{Results}

As of the date of this paper's submission, no cases have been reported at the university. In fact, some measures regarding the wearing of masks have been technically loosened (largely in the case of outdoor activities, in accordance with municipal policies), while student are still required to wear masks indoors and in class. The percentage of students and teachers who do not wear masks (indoors or outdoors) has increased. Temperature checks, while very common throughout the day earlier in the semester, are now only required at the gate upon arrival. A sticker (color coded for the day of the week) is stuck to the individual's clothing to indicate that they have passed the temperature check for that day. Alcohol sanitizer spray bottle are still commonly available and used, and handwashing is practiced. Thus far, online teaching has not been required, to the relief of many teachers and students. Disruptions in terms of classes, in the form of required make-up assignments or lectures, are still in progress, but are being managed with patience from teachers and students. This positive result is based on the joint regulations and support of Taiwan's government and the university in maintaining prevention of COVID-19 infection. Simple guidelines were followed, such as wearing masks, washing hands, reporting symptoms, self-isolation in the case of fever, and effective social distancing. Some guidelines, such as the university's requirement that students have assigned seats, were deemed impractical by some teachers, as students were required to change seats in order to engage in group work, or students would sit according to convenience rather than an assigned seat, which was often difficult for them to find. Furthermore, due to the fact that students do not have fixed classrooms, and chairs or desks may be moved to meet the needs of individual teachers who use the classrooms, thus rendering assigned seating difficult, if not impossible. Nevertheless, overall adherence to national, local, and university guidelines resulted in a smooth semester with few cases of quarantine, no need for online teaching, and only slight disruptions in the semester schedule. 


\section{Discussion}

Taiwan's efforts, as highlighted in the introduction section, could serve as a model for other countries to follow. However, it should be noted that Taiwanese society, population distribution, infrastructure, technology, social norms, openness to online tracking, and other unique factors $[19,20]$ may make it difficult or impossible to emulate in other countries or cultures. However, lessons learned, thus far, from the pandemic include:

a) An early and proactive response in terms of travel restrictions and quarantines;

b) Intensive and extensive, technology-enhanced contact tracing;

c) Promotion of mask wearing, which is already a normative behavior in most East Asian countries [21], and ramped up production of surgical masks; and

d) Provision of clear, concise, infographic resources which can illustrate basic hygiene and disease prevention procedures. University efforts, including the encouraging involvement of the university president, frequent provision of information, strict enforcement of regulations, and proactive preparation in case of the need for online teaching are additional highlights that could be applied to other contexts; again, with similar caveats regarding cultural differences.

\section{References}

1. Steinbrook R (2020) Contact Tracing, Testing, and Control of COVID-19Learning From Taiwan. JAMA Internal Medicine.

2. Liu JY, Chen TJ, Hwang SJ (2020) Analysis of Imported Cases of COVID-19 in Taiwan: A Nationwide Study. International Journal of Environmental Research and Public Health 17(9): 3311

3. Cheng HY, Jian SW, Liu DP, Ng TC, Huang WT, et al. (2020) Contact tracing assessment of COVID-19 transmission dynamics in Taiwan and risk at different exposure periods before and after symptom onset. JAMA Internal Medicine.

4. Cheng HY, Li SY, Yang CH (2020) Initial rapid and proactive response for the COVID-19 outbreak-Taiwan's experience. Journal of the Formosan Medical Association 119(4): 771-773.

5. Chen TY, Lai HW, Hou IL, Lin CH, Chen MK, et al. (2020) Buffer areas in emergency department to handle potential COVID-19 community infection in Taiwan. Travel Medicine and Infectious Disease.
6. Yen MY, Schwartz J, Chen SY, King CC, Yang GY, et al. (2020) Interrupting COVID-19 transmission by implementing enhanced traffic control bundling: Implications for global prevention and control efforts. Journal of Microbiology, Immunology and Infection.

7. Huang YC, Lee PI, Hsueh PR (2020) Evolving reporting criteria of COVID-19 in Taiwan during the epidemic. Journal of Microbiology, Immunology and Infection.

8. Hsu YC, Liu YA, Lin MH, Lee HW, Chen TJ, et al. (2020) Visiting Policies of Hospice Wards during the COVID-19 Pandemic: An Environmental Scan in Taiwan. International Journal of Environmental Research and Public Health 17(8): 2857.

9. Chen YL, Hsu FM, Tsai CJ, Cheng JCH (2020) Efforts to Reduce the Impacts of COVID-19 Outbreak on Radiation Oncology in Taiwan. Advances in Radiation Oncology.

10. Wang CJ, Ng CY, Brook RH (2020) Response to COVID-19 in Taiwan: big data analytics, new technology, and proactive testing. JAMA 323(14): 1341-1342.

11. Cho H, Ippolito D, Yu YW (2020) Contact tracing mobile apps for COVID-19: Privacy considerations and related trade-offs. arXiv preprint. arXiv:2003.11511.

12. Chen FM, Feng MC, Chen TC, Hsieh MH, Kuo SH, et al. (2020) Big data integration and analytics to prevent a potential hospital outbreak of COVID-19 in Taiwan. Journal of Microbiology, Immunology and Infection.

13. Lu N, Cheng KW, Qamar N, Huang KC, Johnson JA (2020) Weathering COVID-19 storm: Successful control measures of five Asian countries. American Journal of Infection Control.

14. Husnayain A, Fuad A, Su ECY (2020) Applications of google search trends for risk communication in infectious disease management: A case study of COVID-19 outbreak in Taiwan. International Journal of Infectious Diseases 95: 221-223.

15. (2020) Taiwan Centers for Disease Control (2020) Press releases.

16. Huang WH, Teng LC, Yeh TK, Chen YJ, Lo WJ, et al. (2020) 2019 novel coronavirus disease (COVID-19) in Taiwan: Reports of two cases from Wuhan, China. Journal of Microbiology, Immunology and Infection.

17. Ko NY, Lu WH, Chen YL, Li DJ, Wang PW, et al. (2020) COVID-19-related information sources and psychological well-being: An online survey study in Taiwan. Brain, Behavior, and Immunity.

18. Hsu WN (2020) COVID-19 and labour law: Taiwan. Italian Labour Law e-Journal 13(1)

19. Chang BBJ, Chiu TY (2020) Ready for a long fight against the COVID-19 outbreak: an innovative model of tiered primary health care in Taiwan. BJGP Open.

20. Hsieh VCR (2020) Putting resiliency of a health system to the test: COVID-19 in Taiwan. Journal of the Formosan Medical Association 119(4): 884-885.

21. Lee TL (2020) Legal preparedness as part of COVID-19 response: the first 100 days in Taiwan. BMJ Global Health 5(5): e002608. 
ISSN: 2574-1241

DOI: 10.26717/BJSTR.2020.28.004594

Jeffrey Hugh Gamble. Biomed J Sci \& Tech Res

(C) (P) This work is licensed under Creative

Submission Link: https://biomedres.us/submit-manuscript.php

$\begin{array}{ll}\text { BIOMEDICAL } & \text { Assets of Publishing with us } \\ \text { RESEARCHES } & \text { - Global archiving of articles } \\ \text { - Immediate, unrestricted online access }\end{array}$

